\title{
Marianne et le garçon noir, sous la direction de Léonora MIANO
}

\section{Carminella Biondi}

\section{OpenEdition}

\section{Journals}

\section{Édition électronique}

URL : http://journals.openedition.org/studifrancesi/16805

DOI : 10.4000/studifrancesi. 16805

ISSN : 2421-5856

\section{Éditeur}

Rosenberg \& Sellier

\section{Édition imprimée}

Date de publication : 1 juillet 2019

Pagination : 202-203

ISSN : 0039-2944

\section{Référence électronique}

Carminella Biondi, «Marianne et le garçon noir, sous la direction de Léonora miano », Studi Francesi [En ligne], 187 (LXIII | I) | 2019, mis en ligne le 01 juillet 2019, consulté le 25 janvier 2021. URL : http:// journals.openedition.org/studifrancesi/16805; DOI : https://doi.org/10.4000/studifrancesi.16805

Ce document a été généré automatiquement le 25 janvier 2021.

\section{$@ \odot \Theta \Theta$}

Studi Francesi è distribuita con Licenza Creative Commons Attribuzione - Non commerciale - Non opere derivate 4.0 Internazionale. 


\title{
Marianne et le garçon noir, sous la direction de Léonora MIANO
}

\author{
Carminella Biondi
}

\section{RÉFÉRENCE}

Marianne et le garçon noir, sous la direction de Léonora MIANO, Paris, Pauvert, 2017, 270

pp.

1 L'écrivaine d'origine camerounaise Léonora MIANO, à côté de son activité de romancière, ou mieux dans le cadre de cette activité, s'intéresse depuis des années aux problèmes des Noirs de la diaspora, des Afrodescendants, des Afropéens, c'est-à-dire des Noirs qui habitent ces régions cicatricielles, nées du rapport entre Afrique et Occident, où trois continents sont impliqués: l'Afrique, l'Europe et l'Amérique. Des régions que les Noirs habitent, mais où ils ont du mal à trouver leur place et même à se trouver. Elle s'était déjà occupée de la «France noire», entre autres, dans Habiter la frontière (2012), où elle avait souligné la situation «d'impouvoir» du Noir habitant l'Hexagone et la difficulté d'apprendre à vivre dans ce territoire de frontière, toujours dans les marges, même si l'on est français. Dans ce recueil, qu'elle introduit de manière éclairante, Léonora Miano donne la parole à des artistes noir.e.s, habitant le monde, qui apportent ici la contribution de leur art pour dire un mode de vie toujours conditionné par l'autre - car l'empreinte de la colonisation tarde à s'effacer - pour essayer de cerner avec lucidité les problèmes liés à ce mode de vie et envisager, je ne dis pas des solutions, qui ne sont pas encore à l'horizon, mais au moins des parcours à frayer pour sortir de cette impasse aliénante et mortifère.

2 Pour son introduction, Léonora Miano a choisi un titre frappant, «Noire hémoglobine», et deux épigraphes de James Baldwin et d'Aimé Césaire qui disent le danger de vivre dans un monde en contradiction avec ses principes. Césaire, en particulier, rappelle à la France son ambiguïté (mais n'est-ce pas, en réalité, l'ambiguïté de tout l'Occident, et peut être de toute civilisation?), d'où découle la difficulté de s'accepter multiple, de se 
renouveler, avec des conséquences négatives pour tous ceux qui l'habitent. "Une civilisation qui ruse avec ses principes est une civilisation moribonde» (Aimé Césaire, Discours sur le colonialisme) (p. 9). L'ouverture n'est pas moins saisissante, car elle se penche sur les mauvais traitements que subissent, de préférence, les Noirs arrêtés par la police, parfois tout simplement pour un contrôle d'identité, traitements qui ne sont que la manifestation la plus voyante d'un mal aux racines profondes: «En France, les brutalités policières - assorties ou non d'injures racistes -, la surveillance constante, prennent vite des allures colonialistes, faisant des groupes minorés, des colonisés de l'intérieur» (p.13). «Colonisés de l'intérieur»: une définition qui en dit long sur la position du commun des Afrodescendants en terre de France, victime d'un processus de racialisation qu'on n'arrive pas à arrêter. D'où le besoin de s'interroger (c'est surtout cela que font les textes réunis dans ce recueil: s'interroger) sur le rôle joué par la notion de race au cours des siècles, car «Il ne suffit pas de clamer l'inanité de la notion de race. Il est nécessaire de savoir à quels besoins répondait son élaboration et, surtout, de quels fardeaux elle leste le legs culturel et politique auquel on ne souhaite pas renoncer» (p. 20). Ce livre, mais en général la recherche des Afrodescendants, vise donc à soulever toute une série de questions fondamentales, qu'on a longtemps esquivées, et qui mettent en cause non seulement le monde des «colonisés», et dans le cas spécifique celui des Noirs de France, ciblé dans le titre, mais les bases du soi-disant «savoir universel», car ce sont aussi les bases de la prévarication d'une civilisation sur les autres. Ainsi, les héros que la France honore ont les mains tachées du sang des Noirs (mais, hélas! de celui des Blancs aussi), la France frappe encore la monnaie de quatorze états subsahariens, elle refuse la restitution au Bénin, qui en en fait la demande officielle, de son patrimoine culturel, conservé dans les musées français... Un vaste champ à défricher, car cet «impouvoir» de l'Afrique fragilise aussi la vie de tous ses expatriés. Cet ouvrage collectif se propose de contribuer à ce défrichement, afin que des «flots de noire hémoglobine déversés» (p.33), puissent naître des «hommes capables d'affronter les ombres de l'histoire pour s'inventer d'autres lendemains» (p. 33). Cette renaissance ne concerne pas seulement les peuples d'Afrique mais, pour employer un terme glissantien, les humanités.

3 Suivent l'introduction, neuf textes de longueur et de nature différentes, qui contribuent, dans leur ensemble, d'un côté, à composer la mosaïque de la difficile et souvent tragique condition du Noir en France (et dans le monde) et, de l'autre, à la recherche des causes de ce mal-être et des possibles chemins que les hommes peuvent emprunter pour laisser derrière eux le jeu destructif du bourreau et de la victime. Ces textes évoquent, même dans leurs titres, cette double finalité: à l'essai qui ouvre la série, Et nous fûmes des écorces (pp. 35-75), de l'artiste afro-caribéenne trans activiste panafricaine Michaëla DANJÉ, qui dit l'humiliation et la lutte, fait suite celui de l'historien béninois-martiniquais Amazat BOUKARI-YABARA, Pour des lendemains noirs d'éclats de soleil (pp. 77-109), qui prône le réveil du peuple noir et un panafricanisme qui réoriente la lecture du monde à partir de l'Afrique. L'essai de l'arctivist (artiste et activiste) togolais ЕLOM20СE, partisan d'une Afrique unie, «Dokuishinono»: reprendre possession de nous même (pp.111-148), est une mise en accusation de la France et de l'Occident, de leur pouvoir de décérébration et de castration, symbolisé par le «signal», dont on marquait l'étudiant africain auquel échappaient, à l'école, des mots de la langue maternelle, et la cravate, symbole de réussite et de succès. Il pose le problème du rééquilibre de forces entre Marianne et l'homme noir, qui va permettre à ce dernier la reconquête de soi et de ses espaces (p.146). Du noir dans le bleu blanc rouge 
(pp. 149-164), de Nathalie ETOKE, professeure d'études afro-diasporiques et francophones au Connecticut College, s'ouvre sur une affirmation qui devrait être, mais n'est pas, une lapalissade: «Dans le contexte républicain, on ne devrait parler ni de Français noirs ni de Noirs français» (p.149). C'est le préjugé raciste qui met en crise (j'ajouterai: qui a toujours mis en crise) les principes fondateurs de la République: liberté, égalité, fraternité, car le corps noir porte «le stigmate des événements passés» (p. 162). La lutte pour l'égalité est menée en France par beaucoup d'associations qui n'arrivent pas à trouver un élément coagulant, comme, par exemple, le «passage du milieu», où se retrouvent tous les Noirs américains, ce qui morcèle les forces et frustre les résultats. Suit un petit «Interlude» (pp. 164-167) où Léonora Miano, avant de donner la parole (un poème et une interview, pp. 168-181) à l'artiste, Akua Naru, originaire de New Haven et résidante à Cologne, élucide certaines références qui pourraient échapper aux lecteurs du poème et explique le choix d'insérer un texte anglais dans le recueil. La façon dont Miano motive l'inclusion de cette «intruse» est du plus grand intérêt, car elle relève d'une orientation nouvelle des recherches afro-diasporiques: «La présence d'Akua Naru dans un ouvrage portant sur le vécu des Afrodescendants en France se justifie par le profil de cette artiste, la transversalité de sa sensibilité afro qui étreint et réunit toutes les populations noires» (p. 167). L'interview se termine par l'éloge, de la part d'Akua Naru, de l'homme noir: «Je pense que les Noirs sont beaux, créatifs...» (p. 181). L'écrivain Insa Sané, né à Dakar et grandi à Sarcelles, dans Fais ce que l'on attend de toi (pp. 183-198), raconte son expérience de jeune noir de banlieue, à qui son père à enseigné à se plier au vouloir de l'autre. Enseignement difficile à digérer et à suivre, d'où les déboires et les dangers qui guettent le plus petit signal de rébellion du jeune noir. Mais Insa Sané veut défendre les droits de ses deux enfants français: «Je refuse qu'ils ne soient chez eux nulle part» (p. 198). Le romancier Wilfried N'Sondé, né à Brazzaville (Congo), a vécu longtemps à Berlin et maintenant réside à Paris. Dans Fauxsemblants (pp. 199-214), il suit, mi sérieux mi ironique, à travers son expérience, en particulier de séducteur à la peau noire, l'évolution, en France, de l'attitude face au Noir, au cours des années 70, 80, 90...

4 Yann Gael, acteur, avec son Journal d'un garçon noir (pp. 15-240), qui porte une sorte de sous-titre ironique: «Introduction à la Liberté, à l'Égalité et à la Fraternité», dit toute sa désillusion face à sa patrie marâtre: «J'ai toujours aimé MA France mais// MA France et TA France jamais ne se // rencontrèrent» (p. 238). Et toutefois l'horizon n'est pas tout à fait bouclé: «Mettre ici un peu de // [LUMIÈRE] (p. 239). En fin de recueil une sorte de poème qui, comme il arrive souvent aux gens qui ont souffert, s'interroge pour nous tous. La guerre du masculin (pp. 241-266, du rappeur, écrivain et metteur en scène D'de Kabal, met en cause la fausse idée de masculinité, celle liée à l'étiquette de «vrai homme», qui est à son avis, un mensonge, un leurre, une entrave qui empêche le difficile parcours vers l'«homme véritable», car c'est un domaine où il n'y a pas de maitres, où chacun doit trouver son chemin. Les «vrais hommes sont - à son avis - des violeurs en puissance» (p. 251), voilà pourquoi il faut un effort pour sortir de cette aliénation, il faut, à l'intérieur «d'un même être, trouver la partie à // nourrir, et le faire quotidiennement» (p. 266).

5 En lisant ce travail collectif, nous sommes véritablement pressés de questions urgentes et vitales, qui nous concernent en tant qu'êtres humains. L'Occident se pose aussi, évidemment, beaucoup de questions, mais il reste inévitablement prisonnier de son passé et de ses certitudes, parfois un peu bancales. On doit reconnaître que les véritables questions, celles qui comptent et qui construiront peut-être les bases du 
monde nouveau, nous viennent surtout des «marges», où des hommes qui cherchent leur point d'ancrage peinent à se retrouver et à trouver des réponses. 